REVISTA ANDALUZA DE ANTROPOLOGÍA.

NÚMERO 3: MIGRACIONES EN LA GLOBALIZACIÓN.

SEPTIEMBRE DE 2012

ISSN 2174-6796

[pp. 7-30]

http://dx.doi.org/10.12795/RAA.2012.i03.02

\title{
ELEMENTOS PARA UNA APROXIMACIÓN TEÓRICA AL EXILIO
}

\author{
CLAUDIO BOLZMAN
}

Universidad de Ciencias Aplicadas de Suiza Occidental y Universidad de Ginebra

\section{Resumen.}

Este artículo plantea algunos elementos que pueden contribuir a la elaboración de una teoría sociológica del exilio, problemática que a pesar de encontrarse regularmente en el tapete de la actualidad se encuentra aún en un nivel embrionario. Se trata, desde una perspectiva definida como dinámica, de considerar tres niveles que se articulan en la problemática del exilio: 1) Las condiciones que empujan los exiliados a expatriarse y que hacen posible su presencia en otra sociedad. 2) Las modalidades a través de las cuales estos actores viven y negocian, colectivamente e individualmente, su doble condición de exiliados con respecto a la sociedad de origen y de refugiados (más o menos reconocidos) con respecto a la sociedad de residencia. 3) La transformación de esas modalidades de negociación a través del tiempo, en particular bajo la influencia de cambios diversos que pueden intervenir tanto en la sociedad de origen como en la sociedad de residencia.

Esta perspectiva implica analizar las migraciones tanto desde la perspectiva del Estado de residencia, como en relación con el Estado de origen de los expatriados. En otros términos se trata de considerar el proceso estudiado en su dimensión transnacional. 
Palabras claves: Exilio, huida, refugiados, perspectiva dinámica, transnacionalismo, niveles de análisis

\section{Abstract.}

This paper develops some elements that could make a contribution to a sociological theory about exile. This issue is usually discussed in the news, but has not yet retained enough attention from scholars. The paper considers, from a dynamic perspective, three dimensions that can be articulated in the study of the exile. 1) The conditions that push exiles to flight their country of residence and that allow their presence in another society. 2) The ways these actors, as groups and individuals, experience their double condition of exiles with respect to their home country and of refugees (more or less recognized) vis-à-vis the host country, and deal with it. 3) The transformation of the ways of dealing with this condition through time under the influence of changes that can take place in the home country as well as in the host country.

This perspective challenges the traditional view of migratory processes as related mainly to situations taking place in the residence country. It underlines the idea that migration processes started in the home country and are continuously related to this country. In other words, the paper stresses the importance of studying this process in its transnational dimension.

Keywords: Exile, flight, refugees, dynamic perspective, transnationalism, levels of analysis

\section{INTRODUCCIÓN}

La noción de exilio es a menudo utilizada de manera metafórica para referirse a diferentes tipos de situaciones vividas por personas que en circunstancias variadas se ven privadas de su lugar en el mundo. En particular, en el ámbito literario o psicológico se evoca ampliamente la figura del exilio como pérdida, a menudo no deseada, de modos de vida anteriores. También se recurre a la figura del exilio para referirse a la ruptura que toda emigración puede significar. A pesar del uso variado y abundante de la noción de exilio, existen pocos trabajos sociológicos o antropológicos que se hayan interesado de manera sistemática por este tipo de fenómeno social.

Si nos referimos al estudio de las migraciones, constatamos que en la mayoría de los casos se considera que los factores económicos y sociales juegan un papel central tanto en la explicación de los movimientos migratorios como en la comprensión del sentido que los emigrantes dan a sus experiencias. La mayor parte de las teorías explicativas de referencia en materia de migraciones no incluyen sin embargo la dimensión del exilio en 
tanto consecuencia de formas de violencia política. Así por ejemplo, uno de los análisis más completos, sistemáticos y críticos de estas teorías es el de Joaquín Arango (2000), el cual no trata de las migraciones de refugiados en su recorrido del tema.

Diversos autores eluden el estudio de las situaciones de exilio aludiendo que en éstas no se pueden encontrar las regularidades que se observan en otros tipos de migraciones, sin dar argumentos sólidos para justificar estas afirmaciones. Sin embargo, los numerosos trabajos que focalizan su interés en las experiencias de los exiliados y los refugiados, a menudo utilizan categorías de análisis similares a las empleadas en el estudio de otros migrantes.

Nuestro objetivo en este artículo es el de plantear algunos elementos que puedan contribuir a la elaboración de una teoría sociológica del exilio, problemática que a pesar de encontrarse regularmente en el tapete de la actualidad se encuentra aún en un nivel embrionario.

Desde nuestra perspectiva, que calificamos de dinámica, nos parece importante tomar en cuenta tres niveles que se articulan en la problemática del exilio:

- Las condiciones que empujan a los exiliados a expatriarse y que hacen posible su presencia en otra sociedad.

- Las modalidades a través delas cuales estos actores viven y negocian, colectivamente e individualmente, su doble condición de exiliados con respecto a la sociedad de origen y de refugiados (más o menos reconocidos) con respecto a la sociedad de residencia.

- La transformación de esas modalidades de negociación a través del tiempo, en particular bajo la influencia de cambios diversos que pueden intervenir tanto en la sociedad de origen como en la sociedad de residencia.

La mayor parte de los trabajos sobre los exiliados/refugiados tratan estas tres interrogaciones de manera separada, lo que produce una visión fragmentada de la cuestión del exilio. Los trabajos que se interesan por la primera interrogación adoptan principalmente una perspectiva macrosocial y se centran en dos grandes temas: los factores socio-políticos que provocan los desplazamientos de población (Zolberg et al., 1986) y las políticas de asilo de los Estados receptores (Caloz-Tschopp, 1998; Castles, 2004). Los trabajos que se centran en las otras dos interrogaciones se sitúan tanto a nivel mesosocial como microsocial y se interesan sobre todo en la adaptación, la integración o la asimilación de los refugiados a las sociedades receptoras (Stein, 1981) o, en el período más reciente, las trayectorias de exclusión a las que éstos son sometidos (Bolzman, 2001; Bauman, 2004; Spicer, 2008). Cuando el pasado de los refugiados es tomado en cuenta, lo es generalmente como factor facilitador o como freno a su incorporación en las sociedades de residencia, o como trauma que deja secuelas psicológicas. 
En este artículo nos centraremos principalmente en las dos últimas interrogaciones, pero sin olvidar su articulación con la primera. Esta perspectiva supone modificar nuestra mirada de los fenómenos migratorios (Oriol et al., 1983) y no sólo considerarlos desde la perspectiva del Estado de residencia, sino también en tanto que proceso comenzado en el Estado de origen de los expatriados y en continua relación con ese Estado de origen. En otros términos, se trata de considerar el proceso estudiado en su dimensión transnacional. Es en razón de ese cambio de perspectiva que preferimos utilizar el concepto de sociología del exilio, en vez del término sociología de los refugiados, que enfatiza la relación con la sociedad de residencia. Además la noción de refugiado es a la vez empleada desde el punto de vista jurídico y desde un punto de vista social más amplio, lo que puede llevar a una cierta confusión terminológica ${ }^{1}$.

En nuestro enfoque consideramos entonces al exilio como una problemática delimitada y precisa, en tanto forma específica de emigración. Se trata de un fenómeno social que puede ser definido como la obligación de dejar su Estado de origen como consecuencia de situaciones de violencia política generalizada o dirigidas a grupos sociales específicos, y de buscar refugio en otro Estado durante un período cuya duración es imprevisible. El exilio se termina cuando las condiciones políticas que dieron lugar a la partida dejan de existir (Bolzman, 1996; 2009).

Esta definición pone énfasis en el hecho de que el exilio es la consecuencia de eventos políticos traumáticos que afectan al conjunto de una sociedad y que provocan profundos trastornos en la vida cotidiana de una parte más o menos importante de la población de esa sociedad. Subraya entonces el hecho que en el caso del exilio existe un lazo estrecho entre fenómenos de tipo macrosocial y fenómenos meso y microsociales, una articulación entre situaciones colectivas y las situaciones vividas por ciertos grupos e individuos. En efecto, el exilio es la consecuencia de una situación de violencia política que marca la historia de una sociedad y deja huellas profundas en aquellos designados como blanco principal de la violencia, los cuales ven afectadas de manera dramática y profunda sus existencias personales, familiares, sociales. Para protegerse, éstos deben buscar protección en otro Estado, lo que dista mucho de ser un proceso automático y evidente, ya que el derecho de asilo no es un derecho individual, sino que un derecho de los Estados, que admiten en el territorio bajo su control, según criterios que les son propios, sólo a las personas que estiman dignas de su protección (Arendt, 1982). Si los exiliados son aceptados en otro Estado, deberán reconstruir sus vidas en un contexto de gran incertidumbre en cuanto a la extensión de su exilio, puesto que es muy difícil

1. Para ser más precisos aún deberíamos utilizar, inspirándonos de Sayad (1991) que habla de una sociología de la emigración/inmigración, la expresión sociología del exilio/refugio, que da cuenta de la complejidad de los procesos a los que se enfrentan los exilados con respecto a su sociedad de origen y a la sociedad de destino. 
prever la duración de la violencia política que dio lugar a su partida. Buscarán además por lo general durante ese período incierto, crear un espacio social transnacional que les permita insertarse en las sociedades de acogida, preservando al mismo tiempo, a su manera y según las posibilidades, los lazos con la sociedad de origen.

El enfoque del exilio que proponemos introduce así una doble perspectiva en el análisis que permite una aproximación a la complejidad del fenómeno estudiado: la dimensión socio-histórica define el marco en el cual se inscribela situación de exilio yla influencia que eventos de un alcance social general pueden ejercer sobre la vida cotidiana de los grupos y los individuos. Pero nuestro enfoque es también comprensivo, en el sentido weberiano, puesto que nos interesamos en el significado que los exiliados otorgan a esos eventos y en la manera que tienen de actuar frente a éstos. En otros términos, consideramos a los exiliados en tanto que actores sociales que intentan elaborar respuestas, en función de sus recursos, de sus lógicas de acción y de los límites que les impone la situación, que les permitan enfrentarse a los acontecimientos. Esas respuestas son dinámicas y pueden modificarse en función del contexto.

\section{FACTORES CONTEXTUALES SOCIO-HISTÓRICOS}

Las situaciones de exilio no pueden entenderse sin una interrogación sobre las dinámicas sociopolíticas que producen la huida de un sector de la población. Otros factores importantes que definen los contornos del exilio son las condiciones del desplazamiento hacia otro Estado, así como las políticas de admisión y de acogida de los Estados receptores. Examinaremos brevemente estas cuatro dimensiones en el espacio de este artículo $^{2}$.

\subsection{Formas de violencia política que conducen a la partida de los exiliados}

Las sociedades de las cuales provienen los exiliados se caracterizan por el hecho de que el Estado ya no detenta el "monopolio de la violencia física legítima" (Weber). En efecto, en estas sociedades el Estado ejerce la violencia de manera ilegítima, o sea que amplios sectores de la población no disponen de formas de protección reconocidas contra la arbitrariedad de las autoridades. No existe por ejemplo un poder judicial independiente que ampare a los opositores al régimen en el poder. $\mathrm{O}$, en un segundo caso, el Estado ha perdido el monopolio de la violencia, que es ejercida por diversas instancias armadas. En este tipo de situación las autoridades no pueden garantizar un mínimo de seguridad a los ciudadanos.

Las situaciones de violencia política pueden ser el resultado de conflictos internos o externos al Estado, pese a que en el mundo contemporáneo es difícil establecer una distinción clara entre estos dos tipos de conflictos. De hecho, casi todos los conflictos tienen una dimensión internacional por la intervención de otros Estados de manera

2. Una presentación detallada con ilustraciones para cada tipo es dada por Bolzman (1992). 
directa o indirecta a través de su apoyo a una de las partes beligerantes (Zolberg et al., 1986).

Es necesario conocer cuáles son las oposiciones mayores que atraviesan una sociedad y que conducen a la exclusión de una parte de la población, para entender quienes son los exiliados y como van a vivir su destierro.

En general es posible distinguir de manera esquemática, cuatro tipos de violencia quellevan al éxodo de un sector de la población: la violencia socio-política, la gestión etnocrática de las tensiones sociales, la lucha por la redefinición de las fronteras geopolíticas y los conflictos interestatales (Bolzman, 1992).

Los exilios de los años 1970 del Cono sur de America Latina constituyen un ejemplo característico de migraciones que resultan de la violencia socio-política. En este caso se enfrentan grupos sociales que se consideran miembros de pleno derecho de la sociedad nacional. Estos grupos tienen intereses y opciones ideológicas radicalmente divergentes sobre quiénes deben dirigir el Estado, de qué manera y con qué objetivos. Las revoluciones y contrarrevoluciones constituyen ilustraciones paradigmáticas de este tipo de situación. Los exiliados provienen del campo de los opositores a aquellos que acaparan el poder. La definición de los opositores puede variar según las modificaciones de la coyuntura política.

En el segundo y tercer tipos, la violencia es ejercida por un grupo étnicamente dominante que se define a si mismo como la encarnación de "la nación". Este impone formas de asimilación o de separación forzadas a los miembros de otros grupos étnicos o religiosos. Si éstos no aceptan la imposición del grupo dominante, su seguridad o incluso su existencia física pueden verse amenazadas.

En el segundo tipo las principales víctimas potenciales son los miembros de lo que Bonacich (1973) llama las "middleman minorities", o sea los grupos que ocupan posiciones socioeconómicas intermediarias en la sociedad y que no tienen una base territorial específica. Estos constituyen a menudo los chivos expiatorios de situaciones de tensión social elevada en tanto prototipos de la figura del "extranjero" (Simmel, 1979) y se ven forzados a escapar cuando el ambiente hacia ellos se torna demasiado hostil. Fue por ejemplo la situación de grupos de asiáticos al final de los años 60 en la Uganda de Idi Amin Dada.

En el tercer tipo de conflicto el poder central se enfrenta a miembros de minorías territoriales que revindican una mayor autonomía o la creación de un nuevo Estadonación. Las tentativas de separación conducen en un primer momento al exilio a un número restringido de personas, pero si el conflicto alcanza un nivel militar, el número de personas que buscan huir de las zonas de combate y la represión sistemática puede aumentar considerablemente. Fue lo que vivieron por ejemplo los albaneses del Kosovo durante la guerra en la antigua Yugoslavia. 
En fin, en el cuarto tipo, la violencia es el resultado de conflictos armados entre dos o más Estados o de la ocupación de un Estado por otros Estados. En este caso, los exiliados pueden reclutarse en el conjunto de la población civil, en función de la amplitud de la violencia, o en ciertos grupos sociales o étnicos que pueden ser el blanco de persecuciones específicas ${ }^{3}$.

Las formas de violencia que conducen al exilio ejercen una influencia sobre la percepción que tienen los expatriados de su nueva situación. Los exiliados excluidos en función de sus divergencias políticas con los grupos que controlan el Estado, situación predominante durante la "guerra fría", se sitúan a menudo en términos ideológicos frente a las dos sociedades de referencia. Aquellos excluidos en razón de su pertenencia a una minoría "intermediaria" tienden a privilegiar los elementos que les permiten conservar la especificidad de su identidad cultural. En el caso de los miembros de minorías autonomistas o separatistas, en aumento en el período de post guerra fría, se observa una combinación de formas de expresión de las dos categorías precedentes, a la vez ideológicas y culturales (Al-Ali et al., 2001). Con respecto a los grupos que huyen los conflictos interestatales, es más difícil discernir una tendencia dominante.

\subsection{El contexto del desplazamiento hacia otro Estado}

Toda situación migratoria es problemática en la medida en que los actores que se desplazan descubren una nueva realidad social cuyas reglas de funcionamiento les son desconocidas. La situación es aún más difícil de enfrentar cuando se trata de una migración forzada, puesto que los exiliados no disponen de un gran control con respecto a las condiciones de desplazamiento. Un problema central es el margen de maniobra limitado del que disponen los exiliados en cuanto a la opción del país de destino. Estos se dirigen hacia lugares cuyo acceso es, tomando en cuenta las circunstancias, relativamente fácil o posible y que son percibidos como comparativamente abiertos a acogerlos. Así, la emigración hacia otro Estado depende de su accesibilidad desde el punto de vista de la cercanía geográfica y/o de su apertura socio-política.

La situación más corriente, que atañe a la gran mayoría de los cerca de 10 millones de refugiados actuales reconocidos por ACNUR, es el desplazamiento hacia Estados vecinos, generalmente situados en el continente asiático o africano. Estos Estados, por razones de política internacional o regional, no pueden oponerse frontalmente a la entrada masiva de una población vecina que huye la violencia ${ }^{4}$. Por lo demás a menudo los instrumentos de los cuales disponen estos Estados para controlar sus fronteras son limitados.

3. Para más detalles véase Bolzman (1996).

4. Sin embargo, es cada vez más difícil atravesar las fronteras de Estados vecinos. ACNUR muestra que el número de refugiados ha ido decreciendo estos últimos años, mientras que el de desplazados internos aumenta constantemente. En el 2005, ACNUR lo estimaba a 25 millones (Revue Réfugiés, 2005, p.7). 
Otro tipo de situación es la del desplazamiento de exiliados originarios de países del "Tercer Mundo" que buscan asilo en las sociedades "centrales" de Europa, Norte América y Oceanía. Se trata sin embargo de una migración selectiva, ya que sólo una modesta fracción de los que huyen de la violencia dispone de los recursos necesarios para dirigirse a un país lejano. En este caso, la admisión de los exiliados dista de ser automática y la legitimidad de su presencia es a menudo cuestionada por los Estados receptores. Sólo una pequeña minoría de entre ellos obtiene el asilo en los Estados del Centro (Harris, 2008; Withol de Wenden, 2008).

Ciertos Estados, como los de la Unión Europea o Australia, externalizan sus fronteras para evitar que los exiliados hagan una solicitud de asilo. En el caso europeo, a Estados de pasaje en Africa del Norte o Europa del Este se les confía el papel de zona tapón para retener a los posibles demandantes antes de que accedan al espacio Schengen (CalozTschopp, 2011). En el caso de Australia, ciertas islas a las que llegan los "Boat people" son consideradas como no aptas para presentar una demanda de asilo (DIAC, 2007).

En todo caso, tanto en los Estados limítrofes como en los Estados del "Norte", la situación de los exiliados dista mucho de ser ideal para enfrentar las consecuencias del desarraigo.

\subsection{Las políticas de admisión de los Estados receptores}

Este punto es complementario del anterior. De hecho son los Estados los que deciden, en principio de manera soberana, el número de los exiliados aceptados en el territorio que controlan y el tipo de exiliados que se beneficiarán de su acogida. También son los Estados los que estipulan cual será el estatus jurídico acordado a los exiliados, en la medida en que el derecho de asilo no es un derecho individual, sino que un derecho de los Estados (Rigaux, 1985; Segur, 1998), o de entidades supranacionales como la Unión Europea (Kunz y Leinonen, 2008). Las decisiones son tomadas en base a criterios jurídicos reconocidos entre los Estados y en función de su evaluación de la situación política y económica interna e internacional. El número de demandantes de asilo aceptados como refugiados puede así variar de manera importante según el origen de los exiliados y según las situaciones coyunturales.

Entre los factores que influencian la legitimidad más o menos reconocida de la presencia de los exiliados en el Estado de destino, podemos citar los siguientes:

- Las afinidades/divergencias políticas o ideológicas entre las opiniones que predominan en el Estado receptor y aquellas defendidas por los exiliados que les costaron ser perseguidos.

- La evaluación por el Estado de destino de la proximidad/distancia cultural, religiosa, étnica, racial con respecto a los exiliados.

- La evaluación por el Estado de destino de la coyuntura económica y de la adaptabilidad de los exiliados a las exigencias de la economía. 
Otros factores que pueden ejercer una influencia son la presentación (o la ausencia de presentación) que hacen los medios de las causas que motivaron el exilio, así como el nivel de movilización de los actores institucionales internacionales (ACNUR, ONGs) y nacionales (partidos, Iglesias, grupos de presión, etc.).

El papel de los actores institucionales nacionales es crucial. Contrariamente a los enfoques que perciben a las sociedades receptoras como relativamente consensuales en su relación hacia el Otro, el tipo de acogida que se hace a cada categoría de exiliados es revelador de las eventuales tensiones y conflictos internos propios a una sociedad. En general, el tratamiento que se le da a cada grupo específico de exiliados se inscribe en el marco de relaciones de poder entre diferentes actores sociales nacionales, tomando en cuenta el contexto internacional.

El ejemplo de los exiliados chilenos en Suiza es ilustrativo de estos factores. La intervención de ACNUR fue importante para sensibilizar a diferentes gobiernos sobre el problema de los refugiados luego del Golpe militar de 1973. Los medios suizos dieron también una amplia difusión a esta situación. Sin embargo, sin la presión y la movilización de los partidos de izquierda, de los sindicatos, de las Iglesias, de diversos grupos humanitarios, el número de exiliados acogidos como refugiados por las autoridades hubiera sido mucho menor (Bolzman, 1993).

Las políticas de asilo son entonces el resultado a la vez de factores endógenos y exógenos a las sociedades de llegada. El estatus jurídico que los Estados receptores otorgan o niegan a los exiliados define el "campo de posibles" en cuanto a su proceso de inserción en la nueva sociedad (Lochak, 1985; Bolzman, 1994).

\subsection{Las políticas de acogida de los Estados receptores}

La acogida es un proceso que hay que distinguir de la admisión. La primera supone la estadía, provisoria o definitiva, de los exiliados en la nueva sociedad.

Que la presencia de los exiliados sea aceptada por las autoridades no significa automáticamente que los exiliados puedan recomenzar una existencia similar a la que conocían en su sociedad de origen antes de que surgiera la violencia política.

Cuando los exiliados se desplazan masivamente hacia un Estado limítrofe, sus dificultades tienen menos que ver con la ausencia de un estatus jurídico reconocido que con la precariedad de las condiciones de vida materiales. Instalados generalmente en campos especiales al margen de los grandes centros urbanos, éstos viven en un mundo relativamente cerrado, un "no man's land" casi sin contactos con la población local. Su situación económica es difícil, ya que dejaron su país de forma precipitada, sin poder disponer de la mayor parte de sus bienes y el campo no es más que un espacio de supervivencia que ofrece justo lo mínimo. Sus posibilidades de desarrollar una actividad autónoma son limitadas y son dependientes de la ayuda de organismos internacionales. 
Esta ayuda en principio no les permite, por razones políticas, que accedan a un nivel de vida similar al de la población nacional. Por otra parte, aunque las diferencias culturales entre la sociedad de origen y la sociedad de acogida sean poco importantes y sus estructuras socio-económicas bastante similares, las autoridades de la sociedad de residencia son reticentes a facilitar la inserción socio-económica de los exiliados, ya que temen que su participación masiva en el mercado laboral pueda cuestionar los ya frágiles equilibrios socio-políticos existentes. Los exiliados son entonces tolerados en el mejor de los casos y las políticas de inserción a mediano o largo plazo casi inexistentes. Esta situación de incertidumbre tiende a prolongarse mientras que no haya una modificación de la situación política que dio lugar al éxodo. En algunos casos, los exiliados son incitados por el contexto de precariedad y por ciertos Estados a transformarse en comunidades de "refugiados guerreros" (Zolberg y al., 1986), lo que impide su inserción en la nueva sociedad y prolonga, a veces por más de una generación, el carácter transitorio de su condición. En consecuencia, algunos exiliados prefieren, a pesar de los riesgos para su seguridad, regresar a su país de origen, mientras que otros esperan la ocasión de reinstalarse en un nuevo país.

Si los exiliados son reconocidos como refugiados u obtienen otro estatus jurídico estable en las sociedades del Centro, van a beneficiarse en principio de los mismos derechos que los nacionales en materia de protección social y de acceso al mercado laboral, lo que constituye una situación privilegiada comparada con la que se puede observar en diversos Estados del "Sur". Pero, como en la práctica la gran mayoría de los demandantes de asilo ven rechazada su demanda, muchos viven situaciones de precariedad, o incluso de ausencia de derechos, que a veces pueden prolongarse por largos años (SánchezMazas, 2011).

Por lo demás, las políticas de acogida y de inserción de los Estados del Centro consideran raramente el pasado de los refugiados, sus expectativas y proyectos como una variable importante. Estas políticas son elaboradas en función de parámetros económicos y políticos propios de las sociedades receptoras, así como de acuerdo con la percepción que las instituciones han elaborado sobre las necesidades de los exiliados. Éstos son raramente consultados. En particular, las políticas de distribución espacial, que llevan a menudo a su dispersión, y las políticas de inserción profesional que resultan en una descalificación laboral, acentúan la desestructuración de la vida cotidiana de los exiliados.

Este desfase entre las políticas de acogida y la necesidad de los exiliados de establecer una cierta continuidad con respecto al pasado, puede ser explicado por dos factores principales.

El primero es la concepción restringida que tienen las instituciones de las sociedades de acogida de las necesidades de autonomía y de inserción de los exiliados. En general, se considera que se han alcanzado estos dos objetivos en cuanto los refugiados se incorporan 
en el proceso de producción. Pero a menudo no hay una preocupación por saber si los empleos a los que tienen acceso los exiliados corresponden a su nivel de calificación. Además, los esfuerzos para facilitar su participación en otras esferas de la vida social fuera de la económica son bastante limitados (Stein, 1979; Bolzman, 2012).

El segundo factor es la percepción etnocéntrica de los exiliados, oriundos en su mayoría de sociedades "periféricas, que predomina en las sociedades y en las instituciones de las sociedades del Centro. Estos son considerados como "menores" inaptos para definir sus propias necesidades, lo cual implica que son las instituciones sociales las que se asignan el derecho de definirlas. Esta visión etnocéntrica resulta principalmente de la asimetría cultural en relación con las posiciones desiguales que ocupan la sociedad de origen y la sociedad de residencia en el sistema de relaciones internacionales (Métraux, 2011).

Examinemos de manera más detallada la problemática de la asimetría cultural. Las relaciones entre las sociedades del Centro y las sociedades del Tercer Mundo fueron en el pasado relaciones de tipo colonial. Hoy en día éstas pueden ser definidas como relaciones de dependencia, es decir como "relaciones de subordinación entre naciones formalmente independientes (Marini, 1972:32). Esta relación de subordinación se ejerce principalmente a nivel económico y tecnológico, pero también se manifiesta, con diversa intensidad, en el plano político, en función de la influencia más o menos directa que los dirigentes de los Estados del Centro ejercen sobre las élites de Africa, Asia y América Latina. De una manera más general, Anne-Catherine Wagner (2006), ha elaborado más recientemente el concepto de "jerarquía de naciones", para referirse a las clasificaciones más o menos implícitas que efectúan los actores sociales con respecto a otros según sus orígenes nacionales en un contexto de mundialización.

De hecho, la situación de dependencia se expresa también en el plano cultural, puesto que las poblaciones del Tercer Mundo son influenciadas por los modelos culturales elaborados en las sociedades de America del Norte y de Europa. En su estudio sobre los exiliados etíopes en Francia y Estados Unidos, Abye (2004), muestra por ejemplo que la mayor parte de éstos se habían ya aculturado a los modos de vida occidentales antes de dejar Etiopía. Montero (1981) muestra tendencias similares en el caso de una parte de los vietnamitas del Sur que se refugiaron en Estados Unidos en los años 1970.

En todo caso, incluso si no se da esta aculturación previa con la misma intensidad, la relación de subordinación se prolonga desde el momento en que los migrantes de las sociedades dependientes se desplazan hacia las sociedades centrales. Los exiliados viven en este caso una situación que podría ser calificada de aculturación obligada (Abou, 1981) o de transculturación. Según Vásquez (1984), se trata de un "proceso que resulta del conflicto desencadenado cuando un grupo de individuos establece relaciones de poder con otros de cultura diferente. El grupo dominante impone relaciones económicas, políticas y sociales que convienen a sus intereses y lleva al grupo dominado a adquirir un mínimo de sus normas culturales para asegurar una dominación adecuada" (1984:119). 
Las situaciones de transculturación conducen a una desvalorización del pasado de los exiliados. Sus saberes, competencias, en particular en el plano profesional, son raramente reconocidos. Sus concepciones de la vida cotidiana no siempre son aceptadas. La desvalorización es también observada en los primeros contactos con las instituciones de ayuda social. Éstas construyen socialmente a los que son denominados "demandantes de asilo", como una "población problemática", que es ubicada en situaciones de dependencia social a la que no estaban habituados. La imagen de si mismos que tenían los exiliados en tanto que seres adultos y autónomos es así cuestionada, lo que dificulta su elaboración de respuestas flexibles que puedan conducir a una inserción social satisfactoria.

Según Saenz (1983), la existencia en las sociedades receptoras de organizaciones políticas, sociales o humanitarias interesadas por la condición de los exiliados puede favorecer una valorización del pasado y hacer posible un comienzo de integración en la sociedad de acogida. Se trata de un contrapeso al proceso de transculturación que los exiliados viven en otros ámbitos de la vida cotidiana. Esta presencia facilita también la reorganización colectiva y el mantenimiento de ciertos lazos con la sociedad de origen. Saenz muestra además que las sociedades de acogida, lejos de ser homogéneas, son atravesadas por tensiones que la presencia de los refugiados contribuye a reactivar. De hecho, la integración colectiva de los exiliados es favorecida cuando existen en la sociedad de acogida actores organizados receptivos con respecto a ellos. Sin embargo, como lo señalan Igonet-Fastinger (1984) o Glick-Schiller y Fouron (1999), en ciertos casos una valorización exagerada del pasado de los exiliados, en particular en el plano político o ideológico, puede tener como consecuencia que éstos se fijen en sus roles anteriores, que se movilicen exclusivamente hacia la sociedad de origen y bloquear así toda tentativa de participación activa en la sociedad de residencia. Sin embargo en otros casos, como lo muestran Ostergaard-Nielsen (2003) y Shain (1999), la movilización por los cambios políticos en el país de origen es perfectamente compatible con un mayor interés por la vida política y social de la sociedad de residencia.

El proceso de incorporación no resulta entonces solamente de los criterios definidos por el Estado de residencia, sino que es objeto de luchas, materiales y simbólicas, en las cuales participan el conjunto de los actores sociales implicados en la situación, incluidos los exiliados. Estos actores disponen sin embargo de un poder desigual y de expectativas diferentes en la relación de fuerzas que se establece entre ellos.

\section{LOS ACTORES SOCIALES FRENTE AL EXILIO}

Los factores que hemos analizado definen el contexto sociohistórico que modela las situaciones de exilio y ejerce une influencia sobre el "campo de posibles" que se abre o se cierra a los exiliados. Sin embargo, estos factores no son suficientes para comprender lo que significa el exilio para los actores sociales que lo viven. La experiencia del exilio y las respuestas que los exiliados elaboran para enfrentar su situación no dependen 
exclusivamente de esos determinantes. En general los comportamientos de los actores sociales no son influenciados mecánicamente por factores socio-históricos globales, por más importantes que estos sean. Ciertas mediaciones, que corresponden a las trayectorias sociales específicas de los grupos y los individuos, incorporan variaciones en la manera que tienen los actores sociales de situarse y de elaborar respuestas frente a un mismo evento general (Lalive d'Epinay, 1975). En el caso del exilio, postulamos entonces la existencia de una pluralidad de maneras de vivir y enfrentar las limitaciones impuestas por esta situación.

\subsection{El exilio en tanto ruptura radical de la vida cotidiana}

La salida hacia el exilio es la consecuencia de una situación de violencia política. Una parte de la población es afectada directamente por esta situación o teme serlo. Frente al peligro y a la inseguridad, las respuestas pueden variar: espera resignada, implicación activa para tratar de cambiar el curso de los acontecimientos, huida de la violencia (si no se es objeto previamente de una medida de expulsión). Los trabajos sobre el exilio latinoamericano muestran que el exilio constituye una ruptura brutal de la cotidianidad de los individuos afectados (Barudy et al., 1980; Carrasco, 1983; Viñar y Viñar, 1989). Esto quiere decir que la persona se ve amputada de pronto de los puntos de referencia espacio-temporales donde se desarrollaba su vida familiar, relacional, profesional, su participación social y política. El exilio afecta la posición global de la persona, el conjunto de sus roles y de su status, su inserción como ser social en una historicidad específica. La partida hacia el exilio es así precedida de una situación de exilio interior o de exclusión en el seno mismo de su propia sociedad que precede a la decisión de partir (Bolzman, 2012).

El exilio es entonces el resultado de un daño profundo al modo de vida de las personas. En otras palabras, al conjunto de maneras de organizar la cotidianidad que les eran propias, que resultaban de la manera específica de articular sus recursos y sus identidades en una sociedad determinada.

Los recursos son el conjunto de "capitales" (Bourdieu, 1979) que poseen los actores y que definen su posición social. Se trata también de medios que pueden ser movilizados para afrontar un cambio de situación. Ciertos eventos centrales afectan el conjunto de los recursos de los actores mientras que otros solamente a una parte de ellos; otros eventos favorecen en cambio la movilización de una parte o del conjunto de los recursos. Los recursos provienen de la historia compartida por los actores en tanto grupo (recursos colectivos) y de los itinerarios sociales específicos de los individuos que componen el grupo (recursos individuales) (Bolzman, 1996).

Los recursos son de diferentes tipos: socioeconómicos, relacionales o sociales, culturales (saberes formales e informales, teóricos y prácticos), sanitarios (posibilidad de vivir 
cotidianamente de manera autónoma sin depender del apoyo directo de otras personas), jurídicos (derechos ciudadanos y capacidad parahacerlos respetar) y simbólicos(Bolzman, 1996). Estos últimos tienen que ver con la reflexividad que permite la distanciación, el análisis y la reinterpretación de un problema, así como el reconocimiento de una situación vivida como problemática y el poder leer de manera dinámica una coyuntura (Bajoit, 1997; Soulet, 2003).

El concepto de identidad sociocultural es particularmente complejo y aquí nos limitaremos a evocar los aspectos directamente en relación con la problemática del exilio. Definiremos la identidad como un dispositivo que permite organizar la movilización de los recursos, orientar la vida cotidiana. Se trata de un sistema de disposiciones cognitivas y representacionales que permite actuar frente a las diversas situaciones que nos toca vivir ${ }^{5}$.

La identidad, tal como la definimos aquí, no es algo substancial, interno al individuo, sino que se construye en interacción con el medio. Ésta se constituye a través de procesos sucesivos de socialización, primero en interacción con grupos primarios y posteriormente con grupos secundarios. A través de estos procesos la persona interioriza maneras de sentir, de pensar y de actuar características de la sociedad en la cual vive y, más precisamente, del medio sociocultural más cercano a ella (Berger y Luckmann, 1971). Esta interiorización le permite situarse en el universo social, a través de la identificación con ciertos grupos y la diferenciación con respecto a otros grupos. La identidad es entonces forjada a partir de las experiencias a las cuales los individuos son confrontados cotidianamente en su entorno social habitual. Al mismo tiempo, ésta sirve para organizar, interpretar y asimilar esas experiencias, para orientar el comportamiento. Se trata de un proceso continuo de elaboración y de reelaboración del "stock de experiencias" acumuladas, en relación con los hechos y los acontecimientos vividos. La identidad es pues una categoría de la práctica y no una suma de rasgos de identificación (Quere, 2006).

Esta estructura está dotada de una cierta flexibilidad que le permite al actor enfrentar situaciones nuevas sin mayores modificaciones de ésta. Pero la elasticidad tiene un limite: si hay cambios en el entorno social que afectan a ciertos recursos valorizados por el actor, la estructura identitaria es cuestionada y debe ser redefinida.

La identidad puede ser afectada por ejemplo por cambios en la situación laboral —como la pérdida durable del trabajo (Lazarsfeld y al., 1981) o la jubilación (Guillemard., 1972)_, por cambios en el estado civil —divorcio, casamiento, viudez (Marris, 1975)—, por la

5. La noción de identidad puede ser considerada aquí como sinónimo de la de ethos. La organización de los recursos en la vida cotidiana está relacionada con lógicas de acción ligadas a sistemas de valores de individuos definidos socialmente (Cf. Lalive d'Epinay y Kellerhals, 1985). Dicho de otro modo, los recursos son movilizados sobre la base de los valores privilegiados por los individuos en un contexto social determinado. 
entrada en instituciones totales - hospital psiquiátrico, cárcel, ejército, sectas religiosas, etc. (Goffman, 1967) - o por la emigración (Oriol, 1984).

El exilio requiere en consecuencia la elaboración de respuestas tanto colectivas como individuales frente a la ruptura de los modos de vida que este implica. Se trata entonces de iniciar un proceso de regulación, pero en un contexto a menudo bastante diferente del que produjo la ruptura. En ese nuevo contexto, los exiliados, a diferencia de los autóctonos, se ven enfrentados en forma abrupta a instituciones, normas, valores, representaciones y prácticas bastante diferentes de las que conocían. En cierta forma deben "nacer adultos" a la sociedad de acogida. Frente a la nueva situación es entonces posible que los conocimientos de "sentido común" (Schutz, 1964) acumulados durante la existencia aparezcan poco útiles y eficaces.

Si tal es el proceso general, las situaciones específicas de partida al exilio pueden influenciar los procesos de regulación. Por ejemplo, los individuos que pudieron anticipar y preparar su partida, generalmente miembros de las clases favorecidas, se encuentran en mejores condiciones para iniciar un proceso de regulación que aquellos que deben salir de manera precipitada hacia un país de asilo provisorio, sin ninguna garantía de inserción ni a mediano ni a largo plazo (Kunz, 1973).

Por otra parte, los exiliados que pertenecen a las "minorías intermediarias", que a menudo han conocido la experiencia de la migración y de vivir en otro contexto sociocultural en sus familias, están en general mejor preparados para enfrentar, al menos en un primer momento, los problemas del descubrimiento de una nueva realidad, que aquellos que no tienen esa experiencia y que salen por primera vez al exterior.

Además, las inserciones sociales previas de los exiliados en sus sociedades de origen, en términos de estatus social, generación, género, pertenencia étnica, religiosa, regional, participación social y política, pueden también influenciar las maneras de vivir el exilio, como pudimos demostrarlo en el caso de los exiliados chilenos en Suiza (Bolzman, 1990, 1996, 2011).

\subsection{El exilio: un doble lazo con la sociedad de residencia y con la sociedad de acogida}

La construcción de un nuevo modo de vida en la sociedad de residencia, implica para los individuos asumir su doble condición de exiliados con respecto a su sociedad de origen, y de refugiados, más o menos reconocidos, con respecto a la nueva sociedad. Esta situación de exiliado/refugiado ha sido sintetizada por Barudy et al. (1980) a través de la metáfora de Jano, el dios romano en el que conviven dos rostros opuestos: uno vuelto al pasado que expresa la ruptura, la separación, el duelo, los sentimientos de culpabilidad y nostalgia. Todo esto crea un sentimiento de muerte social aumentada con la imposibilidad del regreso; el otro mirando hacia el futuro que confronta al sujeto con un medio desconocido, extraño, con un idioma a menudo incomprensible, con costumbres 
diferentes, en donde algunos le expresan solidaridad, una gran mayoría indiferencia y muchas veces las autoridades y las instituciones desconfianza y hostilidad. En estas circunstancias, el porvenir aparece como extremadamente problemático, aunque no exento de posibilidades.

De manera general, los exiliados tratan de construir modos de vida transnacionales, caracterizados por una bilateralidad de referencias (Oriol, 1984), la búsqueda de la preservación de lazos con la sociedad de origen e incluso la tentativa de influenciar el curso de los eventos en la sociedad de proveniencia. La bilateralidad de referencias significa que sus recursos se encuentran repartidos entre ambas sociedades y sus producciones identitarias y simbólicas tienden a articular y reflejar ese doble lazo.

La manera como se construye la bilateralidad de referencia puede variar en función de diversas mediaciones. Ya evocamos el hecho que los exiliados son portadores de una historia comenzada en otro contexto y que su exilio es a menudo el resultado de su inserción específica en la historia de su sociedad. Sus concepciones de su papel social y político, pasado y presente, en su sociedad de origen, así como su evaluación de la evolución de la situación política de ésta, influencian de manera decisiva su relación hacia la sociedad de acogida, en particular su percepción de la duración de su estadía: definitiva o provisoria, y el plazo eventual previsto para retornar al país de origen, que puede situarse en un horizonte muy breve, mediano o muy lejano. Esta percepción temporal ejerce a su vez una influencia sobre el tipo de modo de vida que elaborarán en la sociedad de residencia.

Así para ciertas categorías de exiliados, el punto de referencia principal va a situarse en la sociedad de origen, para otros en la sociedad de residencia y otros buscarán articular sus vidas en torno a ambas sociedades. Por ejemplo, las minorías religiosas o étnicas "intermediarias" consideran generalmente su estadía en la sociedades de acogida como "provisoriamente definitiva" (judíos, armenios, chinos por ejemplo), tendiendo a constituir diásporas (Faist, 2010) y en consecuencia su ritmo de inserción socioeconómica y de aculturación será rápido, preservando al mismo tiempo lazos simbólicos, culturales, sociales y a veces económicos y políticos con la sociedad de origen. En cambio, es más probable que los excluidos políticos o pertenecientes a minorías independentistas perciban su estadía en la sociedad de acogida, al menos durante un primer período, como un paréntesis provisorio, siendo su preocupación central la de mantener la movilización transnacional en relación con la sociedad de origen con vistas a modificar la situación política y a preparar un retorno más o menos rápido (Glick-Schiller y Fouron, 1999).

Por otra parte, los modos de vida que los exiliados van a elaborar y las posiciones sociales que van a ocupar en la sociedad de acogida dependerán también de sus inserciones sociales pasadas y de las oportunidades que se les ofrecen en la sociedad de acogida, en particular de transferir sus recursos en diferentes ámbitos (profesional, social, familiar, etc.), así 
como de la posibilidad de actualizar ciertas formas de vida cotidiana (en particular su relación hacia el tiempo y el espacio, su manera de relacionarse con los demás) propias de su modo de vida anterior, en el nuevo contexto.

De manera general, las comparaciones que los exiliados establecen entre su modo de vida en la sociedad de origen y su situación en la nueva sociedad van a influenciar la relación que establecerán con ambas sociedades.

\subsection{La incorporación a la nueva sociedad: un proceso dinámico}

Los modos de relacionarse tanto con la sociedad de acogida como con la sociedad de origen no son estáticos, sino que se transforman con el tiempo (Vásquez y Araujo, 1987) y son influenciados por eventos socio-históricos que pueden tener lugar en ambas sociedades. En efecto, para la gran mayoría de los actores sociales que se encuentran en situación de exilio, la problemática central es la de la gestión a través del tiempo de la bilateralidad de referencias, o sea la necesidad de inventarse un espacio transnacional que les permita articular y desarrollar los lazos con cada una de las dos sociedades, en función del contexto de cada una de ellas.

Las modificaciones de las situaciones individuales deben también ser puestas en relación con los cambios que intervienen en la comunidad de exiliados: existe a menudo una influencia recíproca entre las trayectorias individuales y las formas que reviste la vida comunitaria. Contrariamente a algunos autores que piensan que en un momento determinado el colectivo puede constituir un obstáculo para la participación de los refugiados en la sociedad de residencia, pensamos que, si bien en ciertos casos el colectivo puede fijarse en formas rígidas quela condenan a su desaparición o a su marginalización, en realidad a menudo emergen nuevas formas de expresión comunitarias que corresponden generalmente a las modificaciones de las posiciones sociales y de los modos de vida individuales.

La incorporación a la nueva sociedad no es sin embargo un proceso lineal, ligada sólo a la temporalidad. Esta puede ser más o menos discontinua y conflictiva. Esto depende por una parte de las políticas de las autoridades de la sociedad de acogida, como lo señalan Portes y Rumbaut (2006), así como también de los eventos políticos y económicos en ambas sociedades y de las orientaciones adoptadas por los exiliados hacia las dos sociedades de referencia. Así por ejemplo, varias situaciones tipo son posibles. Si el Estado de acogida no concibe la integración de los exiliados más que en su mínima expresión, éstos pueden acomodarse si perciben su estadía como provisoria. En cambio, si piensan que se quedarán definitivamente en la sociedad de acogida, en ese caso este tipo de políticas representa una discriminación insoportable. En cambio, una política que favorece una integración progresiva en las diferentes esferas de la vida social (incluido el ámbito político), generalmente es bien aceptada por diferentes tipos de 
exiliados, sobre todo si no es asimilacionista en el plano cultural. En caso de que sí lo sea, puede provocar resistencias, que serán tanto o más importantes en caso de que no haya medidas de integración económicas. Por otra parte, las medidas de integración selectiva (por ejemplo las que favorecen el acceso sin discriminación a la esfera económica, pero que las limitan en el plano político) pueden ser toleradas por la primera generación pero la segunda, en general, más orientada hacia la sociedad de residencia, puede rechazarlas. En efecto, en general los exiliados de la primera generación son más permeables a los cambios en la situación política de la sociedad de origen y a la idea del retorno que la generación siguiente.

El exilio puede también estar definido por diferentes fases que reflejan la manera como los grupos e individuos van cambiando sus modos de vida en función de su percepción de la situación ligada a la emergencia de eventos socio-históricos de fuerte impacto. Por ejemplo, en nuestro estudio sobre el exilio chileno en Suiza distinguimos cuatro grandes fases (Bolzman, 1996): la desestructuración de la vida cotidiana, el descubrimiento del exilio como una realidad durable, la bifurcación de caminos y el final del exilio. La primera fase es el resultado del golpe de estado de 1973, de las peripecias ligadas a las dificultades para encontrar un país de asilo y del choque del descubrimiento de una nueva sociedad, muy diferente de la suya; la segunda resulta de la toma de consciencia de la duración más importante que la prevista del régimen militar y de la necesidad de concebir el exilio a largo plazo. La tercera está ligada a las protestas masivas contra la dictadura en los años 1983-84 y a la manera diferenciada de vivir este evento según los valores de los exiliados (políticos u otros), la fuerza de la idea del retorno y los modos de incorporación a la sociedad suiza. El final del exilio coincide con el final del régimen militar y la transición hacia la democracia en 1990: en esta fase cada exiliado se interroga sobre la cuestión del retorno y sobre la construcción de una nueva legitimidad en caso de tomar la decisión de permanecer en la sociedad suiza.

\subsection{Del exilio al final del exilio}

Desde el punto de vista de la perspectiva adoptada podemos decir que el exilio deja de constituir un fenómeno social cuando los factores sociopolíticos contextuales productores de violencia que dieron lugar al éxodo de una parte de la población desaparecen. A partir de ese momento ya nada se opone, en principio, al retorno de los expatriados. De hecho ya no están obligados a vivir fuera de su país por razones políticas. Su presencia en la sociedad de residencia ya no puede ser legitimada invocando los motivos políticos que permitieron su aceptación como refugiados.

Los actores sociales se encuentran entonces enfrentados a una nueva situación que los acerca a los otros migrantes: tienen la posibilidad de regresar a su país o por lo menos de retomar contacto físico con él. Pueden también quedarse en la sociedad de residencia, pero sobre la base de otra legitimidad que la de refugiados. 
Su situación ya no puede ser definida estrictamente como una situación de exilio, aunque sea la consecuencia de ella. Ese cambio cuestiona los modos de vida elaborados por los exiliados, en el sentido de la necesidad de revisar los lazos establecidos por los expatriados con cada una de las sociedades de referencia. Podemos calificar esta situación de fin del exilio.

Esto no significa que el final del exilio sea vivido por todos los exiliados de la misma manera. Algunos de ellos viven lo que el escritor Mario Benedetti define como el "desexilio". El escritor califica así a la experiencia que viven las personas que regresan a su país de origen y deben reaprender a vivir en éste, puesto que tanto ellas como su país han cambiado con el transcurso de los años. Los que deciden quedarse deben también revisar su relación tanto con la sociedad de origen como con la sociedad de acogida; también experimentan una nueva situación, pero el cuestionamiento de su modo de vida es menos radical: en este caso podemos evocar una situación de post-exilio.

En el caso del exilio chileno en Suiza, el gobierno de este país y el nuevo gobierno chileno, estimulados por las organizaciones chilenas del exterior, ponen en marcha políticas de ayuda al retorno limitadas en el tiempo. Sin embargo sólo una minoría de los exiliados (menos de un tercio) se acoge a estos beneficios. Algunos viven un proceso difícil de desexilio, regresando al cabo de un tiempo nuevamente a Suiza. La mayoría decide por diversas razones (económicas, culturales, educativas, psicosociales, etc.) quedarse en Suiza y construir una nueva legitimidad de su presencia en este país en tanto "residentes". Al mismo tiempo se sienten parte de una diáspora más amplia que guarda una continuidad con la problemática del exilio (movilizaciones por la defensa de los derechos humanos), pero que se abre a nuevos temas similares a los de otros grupos de emigrantes (derecho a voto para los residentes en el extranjero, derecho a la doble nacionalidad, etc.), desarrollando nuevas formas de transnacionalismo (Bolzman, 2011a).

Tanto el desexilio como el post-exilio son entonces situaciones inéditas, pero no pueden ser plenamente entendidas sin referirse a las situaciones de exilio que las han precedido.

\section{SÍNTESIS DE LA PERSPECTIVA PROPUESTA}

La perspectiva que hemos propuesto, como lo hemos enunciado al comienzo de este artículo, puede ser calificada de dinámica y puede ser sintetizada a través de la combinación de tres dimensiones.

Génesis. A través de una sociología cercana a la historia, se trata en primer lugar de analizar el contexto socio-político que define la situación de exilio. En otras palabras, se busca precisar las condiciones que obligan a una categoría de personas a exiliarse, así como también las que determinan su acceso a una nueva sociedad. Esta dimensión permite definir el cuadro macro-social que delimita el campo de posibles para la acción de los exiliados. 
Regulación. A través de un enfoque comprensivo, se trata de describir las maneras a través de las cuales los actores asumen, colectivamente e individualmente, su doble condición de exiliados con respecto a la sociedad de origen y de refugiados, más o menos reconocidos, con respecto a la sociedad de residencia. En otros términos, se trata de analizar los modos de regulación elaborados por la comunidad y los individuos exiliados con el fin de enfrentar las limitaciones impuestas por el contexto socio-político.

Transformaciones. Es importante también estudiar cómo los modos de regulación que pueden ser distinguidos a nivel sincrónico se transforman con el paso del tiempo, al relacionarlos con los cambios socio-políticos que pueden surgir principalmente en la sociedad de origen, pero también en la sociedad de acogida. En la medida de lo posible, si las condiciones lo permiten, es particularmente interesante poder seguir estas transformaciones hasta el término del exilio.

Estas tres dimensiones no deben ser consideradas de manera separada. Se trata en efecto de la distinción analítica de una misma problemática. La dimensión socio-histórica nos permite poner en evidencia el peso de acontecimientos de un alcance general sobre la vida cotidiana de los grupos y los individuos. Pero los límites impuestos por el marco socio-histórico son mediatizados a la vez por las trayectorias sociales anteriores de los actores sociales y por las experiencias diversas vividas a lo largo del recorrido del exilio. Así, tomando como punto de partida una situación general de exilio, somos llevados, al tomar en cuenta la situación de los actores, a distinguir diversas situaciones de exilio. Esto nos permite distinguir una pluralidad definida de modos de regulación de situaciones de exilio. Por lo demás éstas se inscriben en el tiempo. Las respuestas elaboradas por los exiliados para enfrentar las condiciones impuestas pueden modificarse y transformarse. Somos pues conducidos a interrogarnos sobre la dinámica de esos modos de regulación, tanto "interna" como resultado de las influencias de los cambios socio-políticos que intervienen en ambas sociedades.

La perspectiva sociológica propuesta se diferencia de los enfoques que ponen énfasis sobre todo en las regularidades, impidiéndose así el acceso a las especificidades sociohistóricas de los fenómenos de exilio. Esta perspectiva nos permite por otra parte ir más allá de los estudios monográficos, centrados sobre situaciones de exilio particulares, en la medida en que disponemos de un cuadro teórico que nos permite comparar diferentes situaciones de exilio.

Se trata no obstante de una perspectiva que debe ser sometida al examen de la evidencia empírica y que puede ser precisada, completada o modificada a través del estudio de diversas situaciones concretas. 


\section{REFERENCIAS BIBLIOGRÁFICAS}

Abou, S. (1981) L'identité culturelle, Paris : Anthropos.

Abye, T. (2004) Parcours d'Ethiopiens en France et aux Etats Unis: les nouvelles formes de migrations. Paris: L'Harmattan.

Al-Ali, N., Black, R., Koser, K. (2001) “'The limits of transnationalism': Bosnian and Eritrean Refugees in Europe as emerging transnational communities". Ethnic and Racial Studies, Vol. 24, pp. 578-.600.

Arango, J. (2000) "Expliquer les migrations: un regard critique". Revue internationale des sciences sociales, $\mathrm{N}^{\circ} 165$, pp. 329-342

Arendt, H. (1982) "Le déclin de l'Etat-Nation et la fin des droits de l'homme“. En L'impérialisme. Paris: Fayard.

Bajoit, G. (1997) “Qu'est-ce que le sujet?”. En Bajoit, G. y Belin, E. (Ed.), Contributions à une sociologie du sujet. Paris: L'Harmattan.

Barudy, J., Corral, N., Durán, E., Martens, J., Murillo, A., Páez, D. \& Serrano, J. (1980) Así buscamos rehacernos. Represión, exilio y trabajo psicosocial, Louvain: COLAT/CELADEC. Bauman, Z. (2004) Vies perdues. La modernité et ses exclus. Paris: Editions Payot \& Rivages.

Benedetti, Mario. (1984) El desexilio y otras conjeturas. Madrid: El País.

Berger, P. \& Luckmann, T. (1971) The Social construction of Reality. Middlesex: Penguin. Bolzman, Claudio. (1990) «Exilio e identidad sociocultural: Dos generaciones de sudamericanos en Europa». En Riquelme, H., (Ed.) Buscando América Latina. Caracas: Nueva Sociedad.

Bolzman, Claudio. (1992) "Violence politique, exil et politiques d'asile: l'exemple des réfugiés en Suisse. Revue Suisse de sociologie, No 3, pp. 672-693.

Bolzman, Claudio. (1993) Les métamorphoses de la barque. Les politiques d'asile, d'insertion et de retour de la Suisse à légard des exilés chiliens. Genève: Les Editions ies.

Bolzman, Claudio, (1994) «Stages and Modes of Incorporation of Exiles in Switzerland: the Example of Chilean Refugees». Innovation: the European Journal of Social Sciences, 7 , $\mathrm{N}^{\circ}$ 3, pp. 321-333.

Bolzman, Claudio, (1996) Sociologie de l'exil. Une approche dynamique. L'exemple des réfugiés chiliens en Suisse. Zurich: Seismo.

Bolzman, Claudio, (2001) «Politiques d'asile et trajectoires sociales des réfugiés: une exclusion programmée? Le cas de la Suisse». Sociologie et sociétés, Vol. 33, №2, pp. 133158. 
Bolzman, Claudio, (2009), "Chilenos en Suiza. De una comunidad política a una comunidad de residentes". En Escriva, A., Bermúdez, A. y Moraes, N. (eds) Migración y participación política. Madrid: CSIC.

Bolzman, Claudio, (2011) «Modes d'affirmation identitaire des Chiliens en Suisse: Quelles implications pour l'interculturalité?» En Lavanchy A., Gajardo, A. y Derwin, F. (eds.) Anthropologies de l'interculturalité. Paris: L'Harmattan.

Bolzman, Claudio. (2011a) "Transnational Political practices of Chilean migrants in Switzerland", International Migration, Vol. 49, º3, pp. 144-167.

Bolzman, Claudio, (2012) «L’exil : ruptures, épreuves, preuves, résistances». En (Re) Penser l'exil, $\mathrm{N}^{\circ} 1$, le 14 février, http://revue-exil.com/lexil-ruptures-epreuves-preuvesresistances/.

Bonacich, E. (1973) «A Theory of Middleman Minorities». American Sociological Review, Vol. 38, N5, pp. 583-594.

Bourdieu, Pierre. (1979) La distinction. Critique sociale du jugement. Paris: Minuit

Caloz-Tschopp, M.C. (Ed.) (1998) Hanna Arendt et le droit d'avoir des droits. Paris : L'Harmattan.

Caloz-Tschopp, M.C. (Sous la direction) (2011) Résister dans le travail et dans la migration. Paris et Lausanne : L'Harmattan et Unil, 5 vol.

Carrasco, J. C. (1983) Psicología critica y exilio, Lovaina: Mimeo.

Castles, S. (2004) "The factors that make and unmake migration policies". International Migration Review, Vol. 38, N³, pp. 852-884.

DIAC. Department of Immigration and Citizenship (2007) Fact Sheet 65 - New Humanitarian Visa System. www.immi.gov.au/media/fact-sheets/65humanitarian.htm [Consultado el 29 de Mayo de 2009].

Faist, T. (2000) "Transnationalism in international migration: implications for the study of citizenship and culture", Ethnic and Racial Studies, Vol. 23, N², pp. 189-222.

Glick-Schiller, N. y FOURON, G. (1999) "Terrains of blood and nation: Haitian transnational social fields", Ethnic and Racial Studies, Vol. 22, pp. 340-366.

Goffman, E. (1961), Asylums. New York: Doubleday.

Guillemard, A.M. (1972) La retraite, une mort sociale. Sociologie des conduites en situation de retraite. Paris: Mouton.

Harris, N. (2008) Factores económicos y políticos de la libre circulación de las personas". En Pecoud, A. y De Guchteneire, P. (eds.) Migración sin fronteras. Paris: Unesco. 
Igonet-Fastinger, P. (1984) «Approche socio-anthropologique et socio-historique de l'identité», Recherches sociologiques. Vol. 15, pp. 233-240.

Kunz, E. F. (1973) «The Refugees in Flight. Kinetic Models and Forms of Displacement». International Migration Review. Vol. 7, pp. 125:146.

Kunz, J. y Leinonen, M. (2008) "Europa sin fronteras: ¿retórica, realidad o utopía? En Pecoud, A. y De Guchteneire, P. (eds.), Migración sin fronteras. Paris: Unesco

Lalive d'Epinay, C. (1975) Religion, dynamique sociale et dépendance. Le protestantisme en Argentine et au Chili. Paris-La Haye : Mouton.

Lalive d'Epinay, C. y Kellerhals, J. (198) «Paroles des vieux: la place des récits de vie dans une recherche sur l'intégration et la mise à l'écart des personnes âgées». Life Stories, $\mathrm{N}^{\circ} 1$, 29-40.

Lazarsfeld, P., Jahoda, M. y Zeisel, H. (1981) Les chômeurs de Marienthal. Paris: Minuit.

Lochak, D. (1985) Etrangers: de quel droit? Paris: PUF.

Marini, R. M. (1972) «Dialéctica de la dependencia: la economía exportadora». Sociedad y Desarrollo, $\mathrm{N}^{\circ} 1,35-52$.

Marris, P. (1975) Lost and Change, Garden City. N.Y.: Anchor Books.

Metraux, J.C. (2011) La migration comme métaphore. Paris: La Dispute.

Momtero, D. (1979) The Vietnamese Refugees in America: Toward a Theory of Spontaneus International Migration», International Migration Review, Vol.13, pp. 624-648.

Oriol, M. (Ed.) (1984) Les variations de l'identité. Nice: IDERIC.

Oriol, M., Sayad, A. y Vieille, P. (1985) «Inverser le regard sur la migration-immigration». Peuples Méditerranéens, N³1-32, pp. 5-22.

Ostergaard-Nielsen, E. (2003) Transnational Politics: Turks and Kurds in Germany. London/New York: Routledge.

Portes, A., Rumbaut, R. (2006) Immigrant America: A Portrait. Berkeley and Los Angeles: University of California Press, Third Edition.

Quere, L. (2006) "Sens pratique, représentations et théorie critique”, Société, N²6, pp. 153-179.

Rigaux, F. (1985) "La situation juridique et sociale des requérants d'asile en Europe occidentale“. En La forteresse européenne et les réfugiés. Lausanne : Editions d’En Bas.

Sáenz, E. (1983) Les cadres socio-politiques de l'adaptation des réfugiés latino-américains en France, 1964-1979, Thèse de doctorat 3ème Cycle, Université de Paris III. 
Sánchez-Mazas, M. (2011) La construction de l'invisibilité. Genève: Les Editions ies.

Sayad, A. (1991) L'immigration ou les paradoxes de l'altérité. Bruxelles : De BoeckWesmael.

Schutz, A.(1964) «The Stranger: An Essay in Social Psychology». En Colected Papers II: Studies in Social Theory. The Hague: Martinus Nijhoff.

Segur, P. (1998) La crise du droit d'asile. Paris: PUF.

Shain, Y. (1999) Marketing the American Creed Abroad. Diasporas in the U.S. and their Homelands. Cambridge: Cambridge University Press,

Simmel, G. (1979) «Digressions sur l'étranger» in Fritsch P. y Joseph, I. (eds.), L'école de Chicago: naissance de l'écologie urbaine. Paris: Champ Urbain.

Soulet, M.H. (2003) «Faire face et s'en sortir. Vers une théorie de l'agir faible». En Chatel, V.y Soulet, M.H. (eds.), Agir en situation de vulnérabilité. Québec: Les Presses de l'Université de Laval.

Spicer, N. (2008) "Places of Exclusion and Inclusion. Asylum-Seeker and Refugee. Experiences of Neighbourhoods in the UK", Journal of Ethnic and Migration Studies, Vol. 34, ํ2, pp. 491-510.

Stein, B.N. (1981) “The refugee experience: defining the parameters of a field of study”, International Migration Review, Vol. 15, pp. 320-330.

Vasquez, A. (1984) “Les implications idéologiques du concept d'acculturation”. En Cahiers de Sociologie Economique et Culturelle, pp. 83-121.

Vasquez, A. y Araujo, A.M. (1987) Exils latino-américains. La malédiction d'Ulysse. Paris: L'Harmattan.

Vinar, M. y Vinar, M. (1989) Exil et torture. Paris: Denoel.

Wagner, A.C. (2006) Les effets de la mondialisation sur les rapports Sociaux. Thèse d'habilitation, Université de Paris I.

Weber, M. (1971) Economie et société. Paris: Plon.

Withol de Wenden, C. (2008) «Las fronteras de la movilidad». En Pecoud, A. y DE Guchteneire, P. (eds.), Migración sin fronteras. Paris: Unesco.

Zolberg, A.R., Suhrke, A. y Aguayo, S. (1986) "International Factors in the Formation of Refugee Mouvements". En International Migration Review, Vol. 20, pp. 151-169. 